\title{
Further evidence of benefits of a (non-randomised) breast cancer screening programme: the DOM project
}

\author{
H J A Collette, F de Waard, J J Rombach, C Collette, N E Day
}

\begin{abstract}
Study objective-The aim was to demonstrate the benefits of breast cancer screening on mortality.

Design-The study was an evaluation of a breast cancer screening programme by means of different approaches: (1) a casecontrol study, breast cancer deaths being the cases; (2) comparing the numbers of breast cancer deaths in screened and unscreened women; (3) comparing breast cancer mortality before and after start of the programme; (4) comparing breast cancer mortality in different large cities; (5) comparing screening activity with mortality reduction.
\end{abstract}

Setting-The setting was a breast cancer screening programme in the city of Utrecht, the DOM project, for women aged 50-64 years old at intake, birth cohort 1911-1925. The programme started in 1974, and there were five screening rounds up to 1984 . Participation rate in the first round was $72 \%$ (14 697 women).

Main results-(1) Screening was protective against dying from breast cancer, odds ratio 0.52 , with a stronger effect in older women and no evidence of confounding; (2) risk ratio of dying from breast cancer for women in the response group was the same as the odds ratio, 0.52 ; (3) breast cancer death rate after the start of the project was nearly $20 \%$ lower than before the project started; after correcting for women who could not have benefited from screening the reduction was $33 \%$; (4) a rise in breast cancer mortality in birth cohort 1911-1925 seen in other large cities without a screening programme due to aging of the cohort was not seen in the city of Utrecht; (5) mortality reduction followed the screening activity with a time lag of approximately 5 years.

Conclusions-Early diagnosis of breast cancer by mammography reduces breast cancer mortality in women 50-64 years old at intake; different approaches to the evaluation of the project give different estimates of the screening effect, making clear that the effect depends on the intensity of the programme.

f Epidemiol Community Health 1992; 46: 382-386

The first effects on mortality from breast cancer of a mass screening project in the city of Utrecht using both physical examination and (xero)mammography were published in $1984 .^{1}$ The project was called the DOM project, which in Dutch signifies "Diagnostisch Onderzoek (= investigation) Mammacarcinoom". It has a double meaning, because Utrecht is sometimes called the DOM city for its medieval cathedral. As the DOM project used a non-randomised design, we measured the effects on mortality from breast cancer by means of a case controlled study.

In the case-control study, a case was defined as a breast cancer death in a woman born between 1911 and 1925, diagnosis and death occurring after the start of the project. For each case, three controls were selected at random from the local population registries, matched for year of birth. For both the case and the corresponding controls, the screening history was ascertained from the records of the DOM project. The screening history was taken for the time up to and including the date of diagnosis of the case, ie, a "restricted period" compared with the period of the total screening programme. A protective effect of screening against dying from breast cancer was found (odds ratio $0 \cdot 30,95 \%$ confidence interval 0.13-0.70).

No biasing factors were found: in particular the incidence rate of breast cancer in the unscreened group was the same as in the population before the start of the project and the stage of the tumours did not much differ either. ${ }^{2}$ There were no changes in therapy in that period.

Although this was not the first time that a screening project had been evaluated by means of a case-control approach, ${ }^{3}$ and at the same time a screening programme in Nijmegen was evaluated in the same way ${ }^{4}$ and others followed as well, ${ }^{5}$ some criticisms have been raised. Therefore we felt it desirable, in addition to updating the case-control study and searching further for confounding variables, to use alternative approaches to the evaluation of the screening effect.

This paper includes: (1) an update of the case-control study (odds ratio) and further search for confounding factors; (2) an analysis of the results as a cohort study of screened and unscreened women; (3) a comparison of breast cancer mortality in the city of Utrecht before and after start of the DOM project; (4) a comparison of breast cancer mortality in the city of Utrecht with figures from 17 other cities in The Netherlands with 100000 and more inhabitants; (5) a comparison between the number of breast examinations and breast cancer mortality reduction.

\section{Methods}

The DOM project started in 1974. A cohort design was chosen, in which women who did not participate in a particular screening round were 
not invited to the next. Five examinations had been completed by 1984 . The length of the intervals between successive screening rounds was different: $1,1 \frac{1}{2}, 2$, and 4 years respectively. The initial target population consisted of all women living in the city of Utrecht and born between 1911 and 1925, who were thus 50-64 years old at the start of the project. Nearly $72 \%$ of the eligible women $(n=20555)$ participated. Table I gives information about absolute numbers of screened women per screening round and calendar year. More detailed information about the organisation and outcomes has been published previously. ${ }^{26}$

A breast cancer registry was set up and contacts were made with the local authorities and the Central Bureau of Statistics to ensure follow up of the project women. Through their help, it was possible to select controls, to calculate the population at risk and to ascertain the numbers of deaths from breast cancer for the city of Utrecht and other cities in The Netherlands. For the city

Table I The DOM Project: number of screening examinations per screening round and calendar year in the city of Utrecht

\begin{tabular}{|c|c|c|c|c|c|c|}
\hline \multirow[b]{2}{*}{ Year } & \multicolumn{5}{|l|}{ Round } & \multirow[b]{2}{*}{ Total } \\
\hline & 1 & 2 & 3 & 4 & 5 & \\
\hline $\begin{array}{l}1975 \\
1976 \\
1977 \\
1978 \\
1979 \\
1980 \\
1981 \\
1982 \\
1983 \\
1984 \\
1985\end{array}$ & $\begin{array}{l}5327 \\
6940 \\
2430\end{array}$ & $\begin{array}{r}4248 \\
5542 \\
2077 \\
\\
372\end{array}$ & $\begin{array}{r}1432 \\
4620 \\
4022 \\
134\end{array}$ & $\begin{array}{r}1168 \\
7449 \\
4\end{array}$ & $\begin{array}{r}6118 \\
37\end{array}$ & $\begin{array}{r}5327 \\
11188 \\
9404 \\
6697 \\
5190 \\
7955 \\
4 \\
7 \\
6118 \\
37\end{array}$ \\
\hline Total & 14697 & 12239 & 10208 & 8621 & 6155 & 51920 \\
\hline
\end{tabular}

Table II Deaths from breast cancer in the city of Utrecht per calendar year and birth cohort

\begin{tabular}{llll}
\hline & & Birth cohort & \\
\cline { 3 - 4 } Year & Total & $<1911,>1925$ & $1911-1925$ \\
\hline 1970 & 60 & 41 & 19 \\
1971 & 56 & 42 & 14 \\
1972 & 53 & 25 & 28 \\
1973 & 50 & 31 & 19 \\
1974 & 53 & 36 & 17
\end{tabular}

\begin{tabular}{|c|c|c|c|c|c|}
\hline & & & Diag & & \\
\hline & & & $\begin{array}{l}\text { Befo } \\
\text { start }\end{array}$ & $\underset{c t}{A f t e r}$ & Misclassified \\
\hline $\begin{array}{l}1975 \\
1976 \\
1977 \\
1978 \\
1979 \\
1980 \\
1981 \\
1982 \\
1983 \\
1984 \\
1985 \\
1986 \\
1987\end{array}$ & $\begin{array}{l}61 \\
59 \\
51 \\
64 \\
64 \\
62 \\
68 \\
50 \\
51 \\
56 \\
64 \\
68 \\
51\end{array}$ & $\begin{array}{l}38 \\
39 \\
35 \\
50 \\
45 \\
41 \\
52 \\
36 \\
40 \\
40 \\
47 \\
49 \\
29\end{array}$ & $\begin{array}{r}22 \\
14 \\
11 \\
8 \\
8 \\
5 \\
5 \\
4 \\
6 \\
2 \\
4 \\
1 \\
6\end{array}$ & $\begin{array}{l}1 \\
2 \\
5 \\
4 \\
10+1^{\star} \\
14 \\
11 \\
7 \\
4 \\
14 \\
11+1^{\star} \\
16 \\
15\end{array}$ & $\begin{array}{l}0 \\
4 \\
0 \\
2 \\
1 \\
2 \\
0 \\
3 \\
1 \\
0 \\
2 \\
2 \\
1\end{array}$ \\
\hline
\end{tabular}

Source: Central Bureau of Statistics (CBS)
^One breast cancer death missed by the CBS

Table III Distribution of screening in case-control combinations (period 1975-1987)

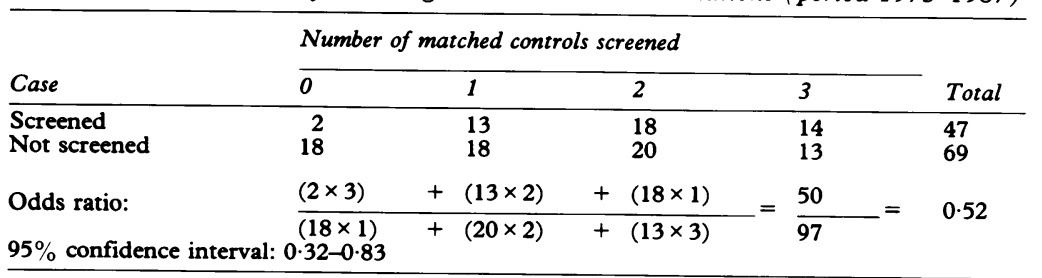

of Utrecht, we were, under strict criteria of privacy, provided with the names of women who died from breast cancer.

\section{Results}

UPDATING OF THE CASE-CONTROL STUDY AND FURTHER SEARCH FOR CONFOUNDING VARIABLES Data are available from 1975 up to the end of 1987 , six years longer than in the original analysis. Table II gives the total number of deaths from breast cancer in the city of Utrecht and from the birth cohort under study. The last group is divided into cases of cancer diagnosed before and after the start of the DOM project; deaths which were "misclassified" (by incorrect coding or misinterpretation) were removed from the casecontrol analysis $(n=18)$. The deaths with breast cancer diagnosed after the start are the cases. Two cases were added (1979 and 1985), being breast cancer deaths missed by the Central Bureau of Statistics. The total number of cases is 116 .

Table III gives the distribution of screened women in the matched case-control study. Of the 116 cases, $41 \%$ (47 women) had been screened in the restricted period, compared with $54 \%$ of the controls (188 out of 348 women; this is less than the participation rate, $72 \%$, as it concerns the restricted period only).

In the control group, 11 women had a breast cancer diagnosed in the period 1975-1987, of whom eight were diagnosed at screening and three after a negative mammogram. One control woman with a screen detected cancer died from a cerebrovascular accident (without progression of the breast cancer).

The odds ratio, 0.52 (with $95 \%$ confidence interval $0.32-0.83$ ), is higher than the value of 0.30 reported previously. Examining the results by quinquennium of birth (table IV) also shows less apparent protection than previously (0.91, 0.42 , and 0.38 versus $0.82,0.31$, and 0.05 respectively ${ }^{1}$ ), with a stronger effect seen in older women. (To check whether removal of the misclassifications influenced the outcomes of the analysis, the odds ratio was recalculated including all misinterpretations. The odds ratio proved to be 0.51 , so no selection had occurred.)

One of the criticisms directed at case-control studies is the difficulty in controlling for all relevant confounding factors. Among factors not considered earlier was weight (the prognosis of breast cancer is known to be influenced by overweight ${ }^{78}$ ). If there had been confounding by this variable, then the controls would be leaner than the cases.

For that reason, data about height and weight of the cases and controls in the period 1975-1983 were collected. In the various hospitals and in the screening centre, weights and heights were available for approximately $65 \%$ of both groups. Table $\mathrm{V}$ shows that there were no great

Table IV Odds ratios (numbers of matched combinations) stratified by birth cohort (period 1975-1987)

\begin{tabular}{lll}
\hline Birth cohort & Odds ratio & $95 \% C I$ \\
\hline $1921-1925$ & $0 \cdot 91(36)$ & $0 \cdot 39-2 \cdot 13$ \\
$1916-1920$ & $0 \cdot 42(37)$ & $0 \cdot 18-1 \cdot 00$ \\
$1911-1915$ & $0.38(43)$ & $0 \cdot 18-0.83$ \\
\hline
\end{tabular}


differences in Quetelet indices between the two groups, demonstrating that the low odds ratio had not resulted from a bias with respect to overweight.

Another factor that might have caused a bias is therapy. As a result of screening, the screen detected cancers were on average at an earlier stage of the disease than the cancers of unscreened women. This being the purpose of screening it would not be appropriate to look upon mode of therapy as a confounding variable. But it might be that as a consequence of their less health conscious behaviour, women who did not participate were less prone to comply with check up visits. A search in the hospital files proved this not to be true: approximately $85 \%$ of the women who had never been screened $(n=110)$ attended regularly, against approximately $80 \%$ of all women with breast cancer $(n=135)$ diagnosed before the start of the project.

Evaluation of the DOM project shows a "healthy screenee effect" with regard to overall mortality. ${ }^{6}$ The question arises as to whether this

Table $V$ Percentage distribution of Quetelet index $\left(H / W^{2}\right)$ of cases and controls

\begin{tabular}{lcc}
\hline Quetelet index & $\begin{array}{l}\text { Cases } \\
(n=33)\end{array}$ & $\begin{array}{l}\text { Controls } \\
(n=108)\end{array}$ \\
\hline$<23$ & $25 \%$ & $19 \%$ \\
$23-26$ & $41 \%$ & $46 \%$ \\
$27-30$ & $9 \%$ & $16 \%$ \\
$>30$ & $25 \%$ & $19 \%$ \\
& $100 \%$ & $100 \%$ \\
\hline
\end{tabular}

Table VI Women years at risk and deaths from breast cancer in response and non-response group

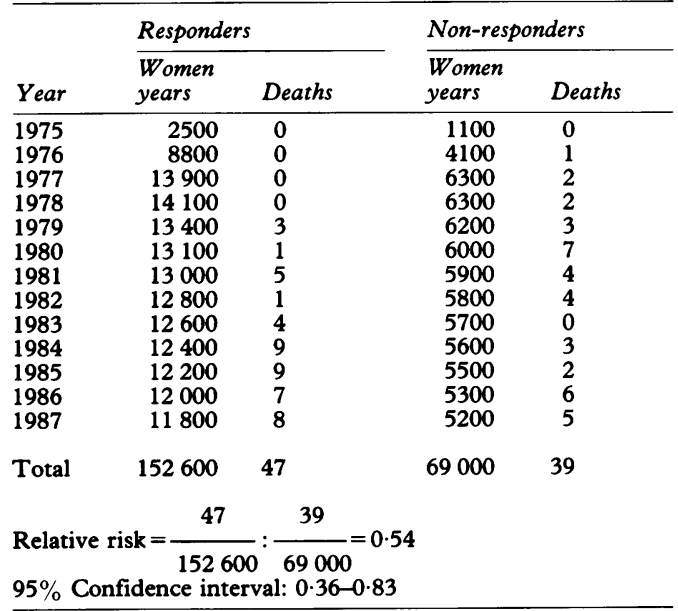

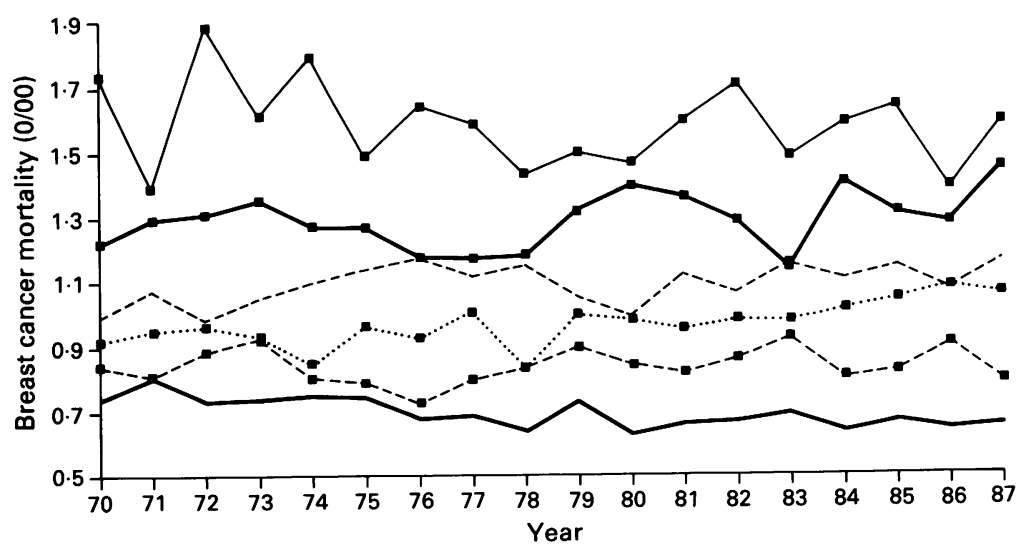

\begin{tabular}{|c|c|c|}
\hline Age 50-54 & $---\quad$ Age 55-59 & $\cdots=\cdots$ Age $60-64$ \\
\hline -- Age 65-69 & $\rightarrow$ Age 70-74 & $\rightarrow-$ Age 75-79 \\
\hline
\end{tabular}

Figure 1 Age specific breast cancer mortality rates in The Netherlands in the period 1970-1987 could have influenced the outcome of the casecontrol study; however, if this had caused a bias it would not have worked in favour of the screening effect, as the screened women have a longer life expectancy and thus are at risk for dying from breast cancer for a longer period. Moreover, as noted previously, ${ }^{2}$ breast cancer incidence in the non-response group was almost the same as the incidence in the total population in the period before the start of the project (19 and 21 per thousand respectively). There is thus no evidence to suggest that the healthy screenee effect influences the outcome of the case-control study.

ANALYSIS OF THE RESULTS AS A COHORT STUDY OF SCREENED AND UNSCREENED WOMEN

The DOM project had a cohort design; a woman who did not participate in the first examination did not receive an invitation for the second examination. The population can therefore be divided into a response and a non-response group on the basis of participation at the first screening round. With the help of the local authorities, it was possible to record when women moved from the city or died and remove them from the population at risk, whether from the responders or the non-responders. With these data and with information regarding the date of first screening of every woman, "women-years at risk" were calculated. Table VI shows the figures for the period 1975-1987. The number of deaths is lower than in table II since women who had breast cancer detected before their date of invitation are omitted. Thirteen of the cases were screen detected breast cancers, 14 cancers were diagnosed in an interval, and 20 were diagnosed after the woman did not attend a subsequent screening round. The risk ratio (relative risk) of dying from breast cancer for women in the response group was $0.52(95 \%$ confidence interval $0.34-0.79)$. The relative risk was thus similar to the odds ratio reported from the case-control study.

COMPARISON OF BREAST CANCER MORTALITY IN THE CITY OF UTRECHT BEFORE AND AFTER START OF THE DOM PROJECT

In The Netherlands during the period 1970-1987, the national age specific death rates from breast cancer showed no consistent trends (fig 1). There is no reason to expect that the rates would be different in the city of Utrecht unless they were influenced by the screening programme. Applying the age specific death rates from the period 1970-75 (ie, before an influence of the programme could be observed) for the period 1978-87 (three years after the start of the project, the programme being in a "steady state" at that time) gave an expected number of breast cancer deaths of 213 . The observed deaths were 171 , a reduction of 42 . Thus the (overall) breast cancer death rate after the start of the project is nearly $20 \%$ lower than before the project started $(p<0.05)$.

It should be borne in mind that among the 171 women from the 1911-1925 cohort who died from breast cancer in the 1978-87 period, a number of women could not have benefited from screening. There were 49 breast cancers diagnosed before the project started, a further 19 diagnosed before the women received an invitation to screening, and four women who moved into the city after the 
start of the project were never invited. Moreover, in 14 women the breast cancer diagnosis on the death certificate proved incorrect on examination of the clinical history (see table II). If one subtracts $86(=49+19+4+14)$ from both the observed $(171-86=85)$ and expected $(213-86=127)$ numbers, one finds a reduction in mortality of $(127-85) / 127=33 \%$ among women eligible for screening.

COMPARISON OF BREAST CANCER MORTALITY IN THE CITY OF UTRECHT WITH FIGURES FROM OTHER LARGE CITIES

The Central Bureau of Statistics provided numbers of deaths from breast cancer in the birth cohort 1911-1925 and numbers of female inhabitants of the 17 cities in The Netherlands with 100000 and more inhabitants. Figure 2 shows moving mortality rates in five year moving averages for 1970-1987. Five year moving averages were chosen in order to reduce fluctuation caused by small numbers. As in the comparison with national figures, the Utrecht rates were initially higher and ultimately lower than the rates in the other cities.

The increase in breast cancer mortality with calendar time seen in the other cities without screening programmes but not Utrecht is

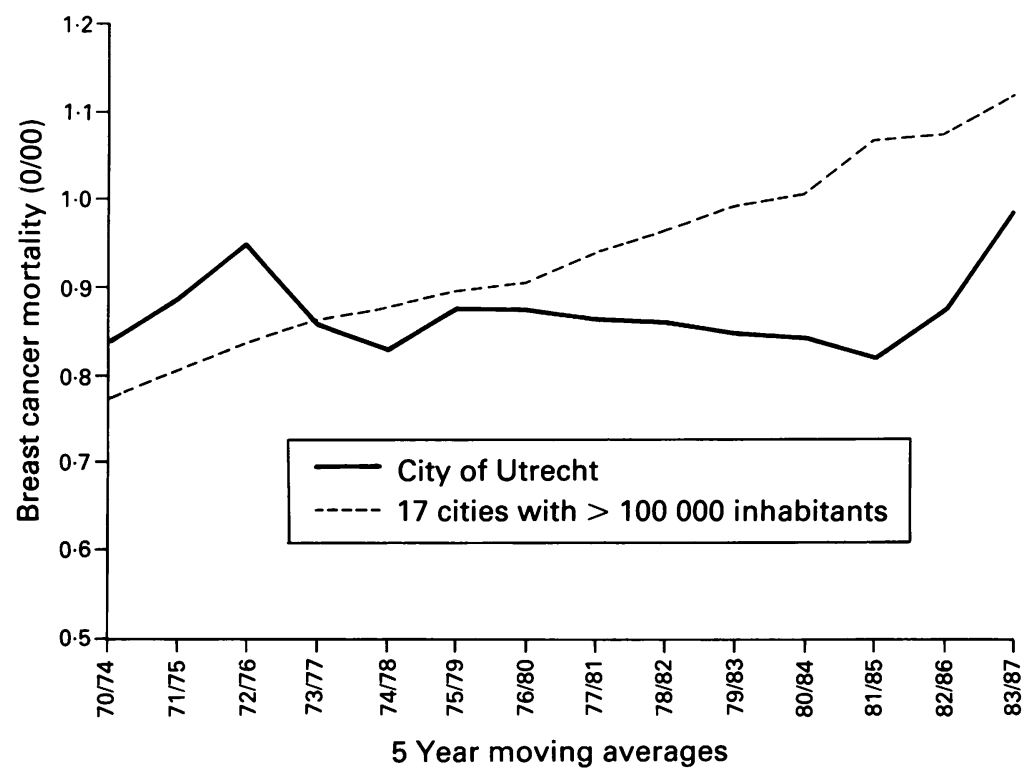

Figure 2 Comparison of breast cancer mortality between Utrecht and other large cities in The Netherlands among women born 1911-1925

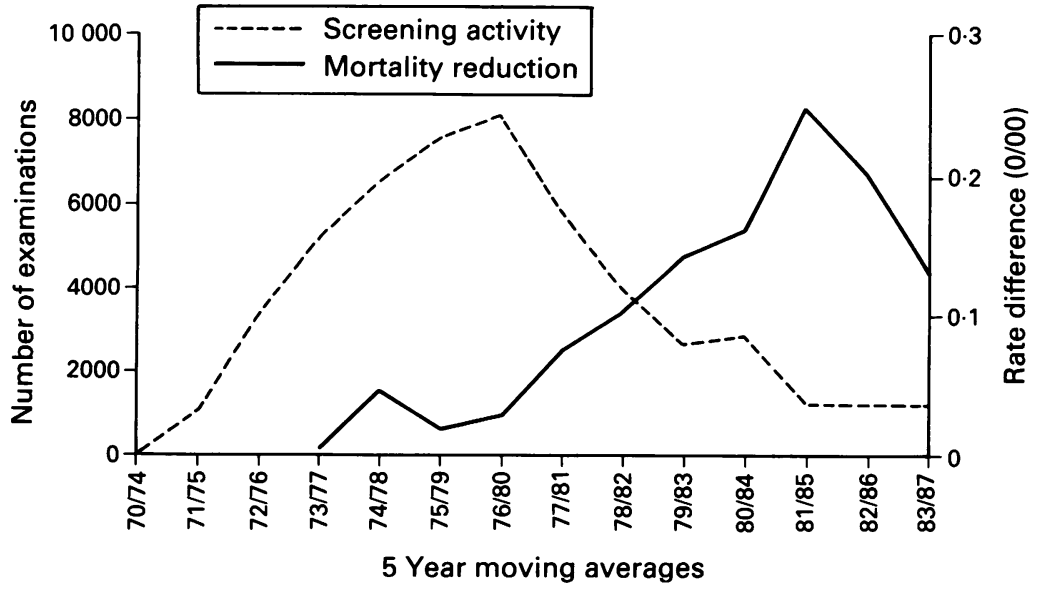

Figure 3 The DOM project screening activity and breast cancer mortality undoubtedly due to aging of the cohort. Comparing cumulative rates for 1978-1987 (restricted to this period as an influence of the programme is not to be expected before 1978) from Utrecht with those from the 17 cities, gives a difference of $10 \%$ (9.4 per 1000 women for 10 years in Utrecht against 10.4 in the other cities, without correcting for the fact that the city of Utrecht started at a higher level). However, the difference becomes smaller after $1981 / 85$. Restricting the cumulative rates to the first six years only (1978-1983) gives a difference of $18 \%(4.9 v 5.9)$.

COMPARISON OF THE NUMBER OF EXAMINATIONS WITH BREAST CANCER MORTALITY REDUCTION

The DOM project was an epidemiological research project and not a service screening programme. This was reflected in its design: a cohort approach and intervals of different length. As a result, screening activity in the city of Utrecht fluctuated (see table I).

Five year moving averages were calculated for the numbers of examinations so that these can be compared with the reduction in breast cancer mortality, the latter being expressed as the difference between the mortality rate of the 17 cities and that of the city of Utrecht. Both are depicted in fig 3. The mortality reduction parallels the screening activity with a time lag of approximately five years, increasing at first and subsequently decreasing.

\section{Discussion}

In this paper, further evidence is presented for the protective effect of breast cancer screening, not only by extending the case-control study and searching for confounding variables and bias in this study, but also by looking at breast cancer mortality rates in the cohort targeted for screening and at the corresponding rates in comparable groups in the rest of The Netherlands.

So far no evidence has emerged that the effect demonstrated in the case-control study was caused by confounding. Moreover, bias free ways of analysing the data, ie, calculating relative risk from the mortality rates in the total screened and unscreened groups, support this conclusion, as does the comparison of breast cancer mortality after the start of the DOM project with the previous rate, showing a 33\% reduction in women eligible for screening. Given $72 \%$ original compliance, this converts into a $46 \%$ reduction among women screened, very close to this case-control result, thus confirming the lack of bias in the case-control comparison.

Analysis of breast cancer mortality reveals a reduction in the cohort targeted for screening, not only when compared with the mortality before the start of the project, but also when compared with that in other large cities without screening programmes. The fact that the effect calculated in this way is smaller than that in the case-control approach can be explained by diluting factors, ie, factors which mask the real effect. There are several such factors: (1) women with breast cancer diagnosed before the start of the project dying from breast cancer during the period under study; (2) women with breast cancer diagnosed before they received the invitation to participate-as it 
takes time to invite and screen the total target population-dying from breast cancer during the study period; (3) misclassification when coding for cause of death, thus allowing breast cancer deaths to be mixed up with deaths from other causes; (4) breast cancer deaths in the nonresponse group. It is possible to correct for the last factor: a protective odds ratio of 0.52 with a population response of $72 \%$ will produce a decrease of $0.48 \times 72 \%=35 \%$ of breast cancer mortality in the total population.

Correction of misclassification is a time consuming job, since it requires information about all death certificates and histopathological reports of breast cancer deaths in the other cities as well. However it is reasonable to suppose that the proportion of misclassification is equal in all cities. The effect of the first factor will disappear with time, as will that of the second factor Correcting for these factors is only possible by extrapolating and making several unprovable assumptions. It is therefore not advisable.

In an earlier paper $^{1}$ the possibility was raised that early detection of breast cancer may only postpone rather than prevent death from the disease, in which case a gradual change in odds ratio to unity over time would be expected. Comparing the odds ratio supports this idea: seven years after the start of the project the odds ratio was 0.30 , while six years later it was 0.52 . However it should be borne in mind that the project had a cohort design and intervals of different lengths; thus the screening activity varied during the years (see table I). The striking pattern parallelism of the screening activity and the mortality reduction, shown in fig 3 , is consistent with the assumption that the effect of screening extinguishes in the course of time. A comparable proof of the effectiveness of a method of early detection of cancer was published by Cramer $^{9}$ in 1974 . He compared various parts of the United States and found a positive correlation between the rate of cytological screening and the size of the decrease in morbidity and mortality from cervical cancer.

As different approaches deal with different difficulties in calculating screening effects it is not surprising that they do not give exactly the same outcomes. Randomised controlled trials such as the HIP study, ${ }^{10}$ the projects in Sweden, ${ }^{1-13}$ and that in Edinburgh, ${ }^{14}$ should give the best estimates of a screening effect, although even in those projects the effects are different and depend on the length of the interval and follow up, the participation rate, the availability of mammography outside the screening programme, etc. (A critical appraisal about the benefits, and side effects, of breast cancer screening has been published lately ${ }^{15}$.) The effects of the DOM project are consistent with the effects from these studies. Moreover there is evidence that after stopping the programme the effect decreases.
CONCLUSION

Further evaluation of the DOM project, a breast cancer screening project, provided additional evidence of benefit of the screening programme Different approaches to the evaluation of this project give different estimates of the magnitude of the screening effect, making clear that the effect depends on the intensity of the programme, such as length of the interval and participation rate. (The quality of the mammography itself has not been discussed in this paper.)

It may be concluded that early diagnosis of breast cancer by mammography reduces breast cancer mortality in the age group 50-64 years at intake. Meanwhile a service screening programme with intervals of two years has been started in the city of Utrecht (as well as in other parts of The Netherlands). In this programme all women will be invited irrespective of whether they have participated in the previous screening rounds. If our conclusions are correct, the protective effect of the screening will increase again in another five years.

This study was funded by the "Praeventiefonds". We thank the staff of the Central Bureau of Statistics, the local authorities, the clinicians and general practitioners, and our coworkers for their help in collecting and analysing the data.

1 Collette HJA, Day NE, Rombach JJ, de Waard F Evaluation of screening for breast cancer in a nonrandomised study (the DOM project) by means of a case control study. Lancet 1984; i: 1224-6.

2 de Waard F, Collette HJA, Rombach JJ, Baanders-Halewijn EA, Honing C. The DOM project for the early detection of breast cancer, Utrecht, The Netherlands. $\mathcal{F}$ Chron Dis 1984; 37: $1-44$.

3 Clarke EA, Anderson TW. Does screening by "Pap" smears help prevent cervical cancer? Lancet 1979 ; ii: 1-4.

4 Verbeek ALM, Hendriks JHCL, Holland R, Mravunac M, Sturmans F, Day NE. Reduction of breast cancer mortality through mass screening with modern mammography. through mass screening

5 Palli D, Rosselli del Turco M, Buiatti E, et al. A case-control study of the efficacy of a non-randomized breast cancer screening program in Florence (Italy). Int $f$ Cancer 1986; 38: $501-4$.

6 Collette HJA, Rombach JJ, de Waard F, Collette C. An update of the DOM project for the early detection of breast cancer. In: Day NE, Miller AB, eds. Screening for breast cancer (UICC). Toronto: Hans Huber Publishers, 1988

7 Boyd NF, Campbell JE, Germanson T, Thompson DB, Sutherland DJ, Meaking JW. Body weight and prognosis in breast cancer. $\mathcal{F}$ Natl Cancer Inst 1981; 67: 785-9.

8 de Waard F, van der Velden JW, de Does M. De invloed van het relatieve lichaamsgewicht op de prognose van borstkanker bij vrouwen. Ned T Geneesk 1985; 129: 454-8.

9 Cramer DW. The role of cervical cytology in the declining morbidity and mortality of cervical cancer. Cancer 1974; 34 2018-27.

10 Shapiro S, Strax $\mathrm{Ph}$, Venet L. Periodic breast cancer screening in reducing mortality from breast cancer. $\mathfrak{f} A M A$ 1971; 215: 1777-85.

11 Tabar L, Fagerberg CJG, Gad A, et al. Reduction in mortality from breast cancer after mass screening with mammography. Lancet 1985; i: 829-32.

12 Andersson I, Aspegren K, Janzon L, et al. Mammographic screening and mortality from breast cancer, the Malmo mammographic screening trial. BMF 1988; 297: 943-8.

13 Gullberg B, Andersson I, Janzon L, Ranstam J. Screening mammography. Lancet $1991 ; 337: 244$.

4 Roberts MM, Alexander FE, Anderson TJ, et al. Edinburgh trial of screening for breast cancer. Mortality at seven years. Lancet 1990; 241: 241-6.

15 Peeters PHM, Verbeek ALM, Zielhuis GA, Vooys GP, Hendriks JHCL, Mravunac M. Breast cancer screening in women over age 50 . A critical appraisal. Acta Radiol 1990; 31: 225-31. 